\title{
O mercado de trabalho e as pessoas com deficiência: um estudo nas grandes e médias empresas do município de Cláudio
}

\author{
Alessandro da Silva - ale3silva5@yahoo.com.br. \\ Universidade do Estado de Minas Gerais - UEMG \\ Josimar Mascarenhas - josimar.m92@ hotmail.com. \\ Universidade do Estado de Minas Gerais - UEMG \\ Valdilene Gonçalves Machado Silva - valdilene.machado@uemg.com.br. \\ Universidade do Estado de Minas Gerais - UEMG \\ Ariadna Rabelo Angeli - ariadna.angeli@uemg.com \\ Universidade do Estado de Minas Gerais - UEMG
}

\begin{abstract}
Resumo
A inserção de pessoas com deficiência no mercado de trabalho é um desafio. As discussões são em torno da sua capacidade produtiva e autonomia. O objetivo desta pesquisa foi identificar, compreender, analisar e discutir os fatores que dificultavam a inclusão das pessoas com deficiência nas empresas de grande e médio porte de forma geral e em especial no município de Cláudio/MG, apresentar sugestões sobre o que pode ser feito para minimizá-los. O universo de pesquisa foram as empresas do município de Cláudio que possuíam mais de cem colaboradores. Ao final constatou-se que as empresas não cumprem a Lei de Cotas, mesmo com lei em vigor, os principais fatores que dificultavam a inclusão das pessoas com deficiência nas grandes e médias empresas é a falta de vagas, pois a empresa não tem interesse em contratar pessoas com deficiência pela falta de capacitação.
\end{abstract}

Palavras chaves: mercado de trabalho, inclusão social, deficiência.

\begin{abstract}
Abstrat
The inclusion of people with disabilities in the labor market is a challenge. Discussions are around its productive capacity and autonomy. The objective of this research was to identify, understand, analyze and discuss the factors that hindered the inclusion of disabled people in large and medium-sized general businesses, particularly in the city of Claudio / MG, make suggestions about what can be done to minimize them. The research universe were the companies Claudio municipality that had more than one hundred employees. At the end it was found that companies do not comply with the Quota Law, even with current law, the main factors that hindered the inclusion of disabled people in large and medium-sized enterprises is the lack of jobs, because companies have no interest in hire people with disabilities by lack of training.
\end{abstract}

Key words: Work. Inclusion. Deficiency. 


\section{Introdução}

A inclusão no mercado de trabalho é um direito das pessoas com deficiência. A Organização Internacional do Trabalho-OIT, na Convenção sobre Reabilitação Profissional e Emprego das Pessoas com Deficiência, criou, em 1983, a Recomendação n. ${ }^{\circ}$ 159, baseada na inclusão social e na acessibilidade, que recomenda que as pessoas com "[...] deficiência deveriam desfrutar de igualdade de oportunidades e de tratamento no acesso, na manutenção e na promoção no emprego que, sempre que for possível, corresponda a sua eleição e a suas aptidões individuais. " (BRASIL, 2007).

O conceito de deficiência, muitas vezes abordado de forma errada, é uma das causas do processo de exclusão. A inclusão das pessoas com deficiência no mercado de trabalho deve ser vista como garantia de dignidade humana, a verdadeira igualdade consiste em tratar igualmente as diferenças.

Esta pesquisa é oportuna, pois percebe-se a grande dificuldade da inserção de pessoas com deficiência no mercado de trabalho, mesmo com a existência de leis que garantam sua inclusão no mercado de trabalho.

Considerando a grande dificuldade de as pessoas com deficiência incluírem-se no mercado de trabalho, o objetivo geral desta pesquisa foi identificar, compreender, analisar e discutir os fatores que dificultam a inclusão das pessoas com deficiência nas empresas de grande e médio porte do município de Cláudio, MG. Para que esse objetivo fosse atingido foram definidos os seguintes objetivos específicos: identificar, na visão das pessoas com deficiência que trabalhavam nas empresas pesquisadas, as barreiras enfrentadas para sua inclusão no mercado de trabalho; identificar os fatores que facilitavam a contratação de pessoas com deficiência pelas empresas pesquisadas; descrever as estratégias utilizadas pelas empresas para cumprirem a Lei de Cotas para pessoas com deficiência; verificar se havia, dentro das empresas pesquisadas, oportunidades de ascensão profissional para as pessoas com deficiência e, por fim, propor estratégias que contribuíam para inclusão das pessoas com deficiência no mercado de trabalho.

A hipótese levantada foi que, entre os principais fatores que dificultavam a inclusão das pessoas com deficiência nas grandes e médias empresas de Cláudio, está no fato de que grande parte das empresas contrata esses profissionais apenas para cumprir uma exigência legal, e isto não assegurava a sua efetiva integração no ambiente de trabalho. Além disso, faltam pessoas com deficiência com a qualificação necessária para atender aos pré-requisitos das empresas contratantes; falta também conhecimento das empresas sobre os processos capazes de garantirem a legítima inclusão, e existiam barreiras físicas, sociais e baixo incentivo dos órgãos públicos.

\section{Revisão Bibliográfica}

\section{O combate ao preconceito}

Ao longo da história, percebe-se que a discriminação a respeito do diferente, seja este representado por um indivíduo ou um grupo de indivíduos, aconteceu de maneira constante. Em decorrência disso, com a evolução da sociedade, foram criadas leis para reprimir tal comportamento uma vez que ele é incompatível com os direitos humanos e com os direitos básicos do cidadão.

Seja pela cor, idade, sexo, religião, opção sexual, deficiência física ou mental, entre outros, sempre houve algum tipo de discriminação. Segundo Franco (2007, p. 12), "A Constituição Federal de 1988, por sua vez, estendeu a publicação do princípio da igualdade, expressamente às pessoas com deficiência e em seu artigo $5 .^{\circ}$ inciso XIII, assegura o livre exercício de qualquer trabalho ou ofício. 
As pessoas com deficiência, por muito tempo, foram mantidas à margem da sociedade, algumas vezes isoladas em hospitais, clínicas e outras instituições, por serem consideradas anormais perante os demais.

\section{Conceitos de deficiência}

A Organização Mundial de Saúde-OMS definiu o termo deficiência como a "[..] ausência ou a disfunção de uma estrutura psíquica, fisiológica e ou anatômica. [...] A expressão pessoa com deficiência pode ser aplicada referindo-se a qualquer pessoa que vivencie uma deficiência continuamente." (DEFICIÊNCIA, 2014).

Deficiente é aquela pessoa que possui alguma limitação, é capaz, porém, de exercer uma atividade e ser tão produtivo quanto qualquer outra pessoa quando utiliza suas aptidões que não dependem de suas limitações; dessa forma, as pessoas com deficiência buscam, cada vez mais, seu espaço na sociedade e no mercado de trabalho.

\section{As pessoas com deficiência no Brasil}

O censo do ano de 2010, realizado pelo Instituto de Geografia e Estatística-IBGE, apontou que no Brasil $23,92 \%$ da população eram portadores de alguma deficiência - visual, auditiva, motora e mental ou intelectual - e que no estado de Minas Gerais 22,62\% da população eram portadores de algum tipo dessas deficiências (OLIVEIRA, 2012). No município de Cláudio, localizado em Minas Gerais, de acordo com dados da Prefeitura Municipal/2014, existiam 6.697 pessoas com deficiência, o que correspondia a $24,28 \%$ do total da população do município. Esse número elevado foi atribuído ao grande número de fundições e metalúrgicas existentes no município que utilizavam equipamentos e máquinas perigosas no seu manuseio e no processo de manufatura artesanal. Fator que contribuí para ocasionar acidentes de trabalho que deixavam sequelas permanentes.

Em relação ao número de empregos, Oliveira (2012) afirma que, segundo informações da Relação Anual de Informações Sociais-Rais no ano de 2011, no Brasil 325,3 mil postos de trabalho foram ocupados por pessoas com deficiência, o que corresponde a $0,70 \%$ do total de vínculos empregatícios, sendo que desse total $65,74 \%$ eram ocupados por homens e $34,26 \%$ por mulheres, e o maior número desses vínculos empregatícios estavam entre as pessoas que possuíam o ensino médio completo, e o menor número de vínculos estava entre as pessoas analfabetas.

\section{Lei de Cotas e legislações posteriores}

Em 2004 foi aprovada a lei da inclusão social no Brasil, Lei de Cotas, que determina que as empresas devam ocupar uma percentagem das vagas com pessoas com deficiência. Em 26 de agosto de 2009 entra em vigor o Decreto 6.949, que promulgou a Convenção Internacional sobre os Direitos das Pessoas com Deficiência e seu Protocolo Facultativo, com o propósito de proteger e assegurar o exercício pleno e equitativo de todos os direitos humanos e liberdades fundamentais por todas as pessoas com deficiência e promover o respeito pela sua dignidade; em 06 de julho de 2015 o Estatuto da Pessoa com Deficiência, Lei 13.146/2015, destinada a assegurar e a promover, em condições de igualdade, o exercício dos direitos e das liberdades fundamentais por pessoa com deficiência, visando à sua inclusão social e cidadania.

A lei que garante a inclusão das pessoas com deficiência no mercado de trabalho é a Lei $n{ }^{\circ}$ 8.213/1991, que em seu art.93 determina que:

A empresa com 100 ou mais funcionários está obrigada a preencher de dois a cinco por cento dos seus cargos com beneficiários reabilitados, ou pessoas portadoras de deficiência, na seguinte proporção: até 200 funcionários $2 \%$, de 201 a 500 funcionários 3\%, de 501 a 1000 funcionários 4\%, de 1001 em diante funcionários 5\%. (BRASIL, 1991) 
Para a inclusão no mercado de trabalho "[...] é necessário assegurar as condições de interação das pessoas com deficiência com os demais funcionários da empresa e com todos os parceiros e clientes com os quais lhes caiba manter relacionamento." (GIL, 2002, p. 11).

Portanto, as empresas precisam preparar seu público interno para receber as pessoas com deficiência e para cumprir o art. $4^{\circ}$ do Estatuto da Pessoa com deficiência "Toda pessoa com deficiência tem direito à igualdade de oportunidades com as demais pessoas e não sofrerá nenhuma espécie de discriminação."

\section{Barreiras para a inclusão das pessoas com deficiência no mercado de trabalho}

Entre as principais barreiras para a inclusão das pessoas com deficiência no mercado de trabalho, de acordo com Cavalcante e Jorge Neto (2006), estão: a carência de qualificação profissional; a carência dos sistemas de habilitação e reabilitação e a falta de estímulos econômicos que facilitem a sua contratação pelas empresas. Cavalcante e Jorge Neto (2006, p. 4) ressaltam ainda: "A verdade parece estar na combinação dos dois argumentos. Os portadores de deficiência não necessitam de medidas preferenciais, mas sim de remoção das barreiras que impedem a sua inserção no mercado de trabalho". Violante e Leite (2011, p. 16) também ponderam: "O principal aspecto que dificulta a contratação e o posterior exercício do trabalho das PCD é com relação à estrutura física das empresas, ou seja, às barreiras arquitetônicas para locomoção das PCD dentro das dependências das empresas".

\section{As pessoas com deficiência nas organizações e a Prática de Recurso Humanos}

A contratação de pessoas com deficiência é um fenômeno recente, pois suas representações passaram por sucessivas transformações até ser reconhecidas como pessoas com direito e dignidade humana e consequentemente com direito ao trabalho. O trabalho no sentido de emprego ou atividade salarial representa para as pessoas com deficiência uma fonte de recompensas simbólicas, tais como: sentimentos de valorização pessoal, conquista do direito ao trabalho, capacidade de contribuir para a renda familiar, entre outros, além do sentimento de dignidade dar lugar ao da vitimização (OLIVEIRA, 2006).

As pessoas com deficiência que têm a oportunidade de trabalhar sentem discriminação porque as empresas muitas vezes contratam apenas para cumprir a lei e, não, pela preocupação da inclusão social. Muitas vezes acontecem situações de desvios de função, remuneração incompatível com a atividade exercida, desigualdades de salários entre as pessoas portadoras de deficiência física e as demais, sonegação de informações sobre a empresa e rotinas de trabalho, entre outras políticas excludentes, o que contribui para tal sentimento. Atitudes de iniciativa de inclusão dos empregadores e dos próprios empregados são as armas para superar o sentimento de discriminação (OLIVEIRA; ARAÚJO; ROMAGNOLI, 2006).

De acordo com a Federação Brasileira de Bancos-Febraban (2006, p. 23), "A empresa que contrata colaboradores com deficiência deve ter um programa estruturado de adequação de estrutura física, recrutamento, seleção, contratação e desenvolvimento de pessoas e não apenas contratar para cumprir a lei".

A contratação de pessoas com deficiência requer ações e práticas de trabalho especiais. Freitas $(2009$, p. 5) cita três fatores fundamentais:

Fator 1 - Sensibilização: este fator focaliza a percepção das pessoas em relação às ações da empresa no sentido de sensibilizar as chefias e funcionários para a inserção de pessoas com deficiência e fornecer informações sobre saúde e segurança no trabalho às pessoas com deficiência contratadas.

Fator 2 - Adaptações: este fator identifica a percepção das pessoas em relação às adaptações nas condições e instrumentos de trabalho, realizadas pela empresa, para facilitar a inserção de pessoas com deficiência.

Fator 3 - Práticas de RH: este fator indica a percepção das pessoas em relação à adequação das práticas de seleção, treinamento, promoção e 
transferência, realizadas pela empresa, com vistas a inserir as pessoas com deficiência. (FREITAS, 2009, p. 5.)

Cabe ressaltar também que às vezes a própria empresa torna o mercado pouco atrativo para as pessoas com deficiência. Segundo Haber (2015) as vagas ofertadas pelo mercado de trabalho às pessoas com deficiência não são muito atrativas por ser mais operacionais. Os gestores ainda não consideram as pessoas com deficiência em cargos mais estratégicos, pois têm uma visão equivocada desses profissionais, quando consideram que eles geram mais custos em decorrência da acessibilidade, ou que são menos produtivos. Assim sendo, os profissionais responsáveis pela seleção e contratação de funcionários nas organizações devem passar por constantes treinamentos para que estejam preparados para lidar com a diversidade.

\section{Metodologia}

O objetivo deste trabalho foi identificar, compreender, analisar e discutir os fatores que dificultavam a inclusão das pessoas com deficiência nas empresas de grande e médio porte do município de Cláudio/MG. Para atingir este objetivo foi realizada uma pesquisa classificada quanto aos objetivos como descritiva, pois o objetivo foi descrever os fatores que dificultavam a inclusão das pessoas com deficiências nas grandes e médias empresas do município de Cláudio. Quanto aos procedimentos técnicos foi realizada uma pesquisa bibliográfica em livros, materiais já publicados, artigos e internet. Quanto à forma de abordagem, esta foi qualitativa. O universo da pesquisa foram as empresas de grande e médio porte do município mineiro de Cláudio que possuíam mais de cem colaboradores e os funcionários com deficiência que trabalhavam nessas organizações. Para classificação das empresas foi utilizado o critério de classificação adotado pelo Serviço de Apoio às Micro e Pequenas Empresas (SEBRAE/2014) por número de funcionários.

O município de Cláudio possuía três empresas de grande porte e dez empresas de médio porte. Participaram da pesquisa todas (100\%) as empresas de médio e grande porte que possuíam mais de cem funcionários. Este critério foi adotado, pois, de acordo com a Lei n. ${ }^{\circ} 8.213$, de julho de 1991, em seu art. 93, somente as empresas que possuem mais de cem colaboradores são obrigadas a preencher de $2 \%$ a $5 \%$ dos seus cargos com beneficiários reabilitados ou pessoas portadoras de deficiência. Para a escolha dos colaboradores com deficiência foi utilizada a amostra intencional, pois responderam à pesquisa os funcionários indicados pelas empresas, pois elas não permitiram que os pesquisadores abordassem seus funcionários. As empresas pesquisadas possuíam juntas, um total de dezoito colaboradores com deficiência; destes quinze, ou seja, $83 \%$ responderam à pesquisa.

Foi definida como instrumento de pesquisa a entrevista, tanto com os gestores de recursos humanos quanto com os colaboradores com deficiência. Dessa forma foram elaborados dois tipos de questionários: um para os gestores de recursos humanos, cujo objetivo foi conhecer a visão da empresa; e outro para os colaboradores com deficiência, com o objetivo de conhecer a sua visão sobre o problema de pesquisa. Os questionários, depois do pré-teste, foram aplicados aos gestores de recursos humanos e aos colaboradores com deficiência. Os dados levantados por meio dos questionários foram tabulados e transformados em gráficos para ser interpretados e analisados.

O município de Cláudio está localizado no centro-oeste de Minas Gerais. De acordo com o Instituto Brasileiro de Geografia e Estatística-IBGE/2016, possuía em 2015 uma população estimada em 27.827 habitantes e a área da unidade territorial era de $630,706 \mathrm{~km}^{2}$. O município é conhecido como um dos maiores pólos de fundições e metalúrgicas do Brasil, com destaque para a produção de móveis em alumínio, peças de ferro fundido e outros. A economia local em 2013 tinha 2.940 estabelecimentos, que geraram 8,36 mil empregos (DATAVIVA, 2016). Conforme dados da Prefeitura Municipal (2014), existiam 6.697 pessoas com deficiência, o que correspondia a $24,28 \%$ do total da população da cidade. 


\section{Análise dos Resultados}

O município de Cláudio possuía três empresas de grande porte e dez de médio porte. Destas, nove participaram da pesquisa, ou seja, $69 \%$ do total de empresas de grande e médio porte, sendo $33 \%$ de grande porte e $67 \%$ de médio porte, sendo que a maioria delas eram indústrias. Para a pesquisa foram selecionadas apenas as empresas que possuíam mais de cem colaboradores, considerando que, por força de lei, estavam obrigadas a preencher um percentual de seus cargos com beneficiários reabilitados, ou pessoas portadoras de deficiência. Sendo assim, todas as empresas (100\%) que possuíam mais de cem colaboradores e que eram de médio ou grande porte participaram da pesquisa. Das empresas pesquisadas apenas 33\% cumpriam a Lei de Cotas (Lei n. ${ }^{\circ}$ 8.213/1991).

O intuito inicial foi conhecer a visão das empresas, por meio de seus gestores de recursos humanos, sobre os fatores que facilitavam e dificultavam a contratação de pessoas com deficiência e sua expectativa em relação ao trabalho dessas pessoas. A pesquisa demonstrou que $90 \%$ delas contratavam pessoas com deficiência apenas para cumprir a Lei de Cotas e $10 \%$ contratavam por outros motivos. Sobre o empenho das empresas em incluírem as pessoas com deficiência no mercado de trabalho, identificou-se que apenas $40 \%$ estavam empenhadas em promover a inclusão; $20 \%$ às vezes se empenhavam; $10 \%$ raramente se empenhavam; e $30 \%$ não tinham essa preocupação. Quando questionadas sobre as estratégias utilizadas para cumprimento da Lei de Cotas, 30\% afirmaram que a empresa contratava pessoas com deficiência apenas para funções que pudessem ser realizadas por elas sem nenhum tipo de risco. Os outros $70 \%$ das organizações pesquisadas deixaram de responder esta pergunta.

A Lei de Cotas determina que empresas com cem a duzentos funcionários estão obrigadas a preencher $2 \%$ de seus cargos com beneficiários reabilitados ou pessoas com deficiência; de 201 a quinhentos funcionários, 3\%; de 501 a mil funcionários, 4\%; e a partir de 1001 funcionários, 5\% (BRASIL, 1991).

Todas as empresas pesquisadas afirmaram que o principal motivo para não contratar pessoas com deficiência era a falta de capacitação profissional dessas pessoas para os cargos almejados. Outro fator relevante, identificado pela pesquisa, foi que $40 \%$ das empresas afirmaram que seus funcionários com deficiência não tinham buscado capacitar-se; $30 \%$ alegaram que raramente eles buscavam capacitação; $20 \%$ declararam que às vezes eles buscavam capacitar-se; e apenas $10 \%$ das empresas disseram que seus funcionários com deficiência procuraram capacitar-se.

Apesar de grande parte das organizações afirmar que seus colaboradores com deficiência não buscam capacitar-se, a maior parte delas $(60 \%)$ alegou que oferecia treinamento adequado quando contratava pessoas com deficiência.

A Lei . $^{\circ}$ 10.098/2000 define normas e critérios para se promover a acessibilidade das pessoas com deficiência ou com mobilidade reduzida. Sobre este tema, 30\% das empresas pesquisadas afirmaram que sinalizaram a empresa para melhor orientação dessas pessoas; $10 \%$ construíram rampas de acesso; $40 \%$ adaptaram os banheiros; e 20\% fizeram outras adaptações necessárias. Entretanto, apenas $30 \%$ preparavam seus colaboradores para lidarem com as pessoas com deficiência; $40 \%$ às vezes as preparavam; $10 \%$ raramente preparavam seus funcionários para receberem colegas com deficiência; e 20\% das empresas não tinham esta preocupação.

Com a pesquisa foi possível também traçar um perfil das pessoas com deficiência que trabalhavam nas organizações pesquisadas. Identificou-se que $79,92 \%$ eram homens e $20,08 \%$ eram mulheres. A maioria possuía idade entre trinta e cinquenta anos $(73,36 \%) ; 13,32 \%$ tinham menos de trinta anos; e os outros 13,32\% tinham mais de cinquenta anos. A maioria trabalhava na empresa havia mais de dez anos (66,66\%); 20,08\% trabalhavam havia mais de cinco anos e menos de dez anos; e 13,32\% estava na empresa havia menos de cinco anos. Quanto ao grau de instrução, a grande maioria $(73,36 \%)$ possuía apenas o ensino fundamental; 26,64\%, apenas o ensino médio; nenhum possuía ensino superior. Quanto às deficiências, eles possuíam as mais diversas deficiências, a física, a auditiva, a visual, a mental e a múltipla. 


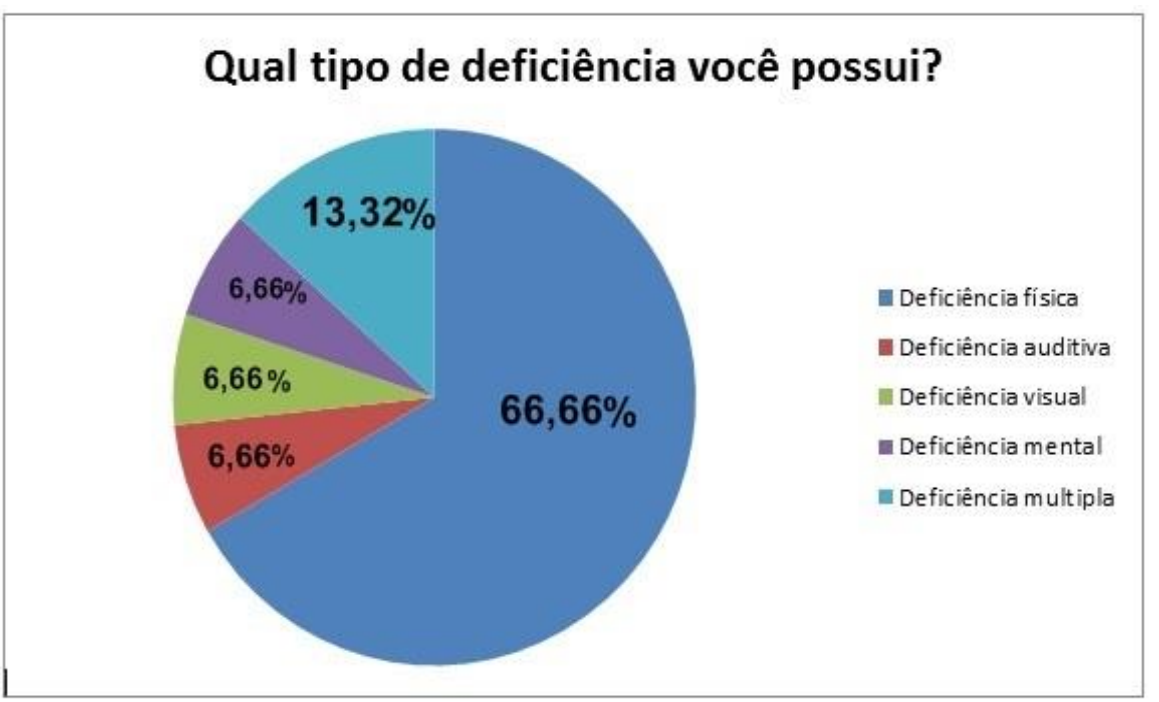

Gráfico 1 - Tipos de deficiência dos colaboradores das grandes e médias empresas Fonte: Dados da pesquisa

Pode-se observar no Gráfico 1 a predominância da deficiência física, que representou 66,66\%; $13,32 \%$ dos colaboradores possuíam deficiência múltipla; e as demais deficiências, física, auditiva, visual e mental representavam $6,66 \%$ cada uma. Este percentual maior de pessoas com deficiência física pode ser atribuído ao grande número de fundições e metalúrgicas existentes na cidade que utilizavam equipamentos e máquinas perigosas que precisavam de atenção especial no seu manuseio e ao processo de manufatura que ainda era muito artesanal. Estes fatores contribuíam para acidentes de trabalho que deixavam sequelas muitas vezes permanentes, principalmente nos membros superiores.

Segundo os colaboradores com deficiência, os fatores que mais contribuíram para sua inclusão no mercado de trabalho foram já terem experiência profissional (79,93\%), indicação de amigos e parentes $(13,32 \%)$ e muita oferta de vagas para pessoas com deficiência $(6,66 \%)$.

Sobre as dificuldades para se incluírem no mercado de trabalho, $86,58 \%$ disseram que enfrentaram dificuldades e 13,32\% disseram que não. O Gráfico 2 apresenta, na visão das pessoas com deficiência que trabalhavam nas empresas pesquisadas, os principais fatores que dificultaram a sua entrada no mercado de trabalho. A falta de vagas destinadas às pessoas com deficiência e a falta de interesse das empresas em contratá-las eram os dois principais motivos, representando 19,98\% cada um. A falta de capacitação profissional era outro motivo apontado por $13,32 \%$.

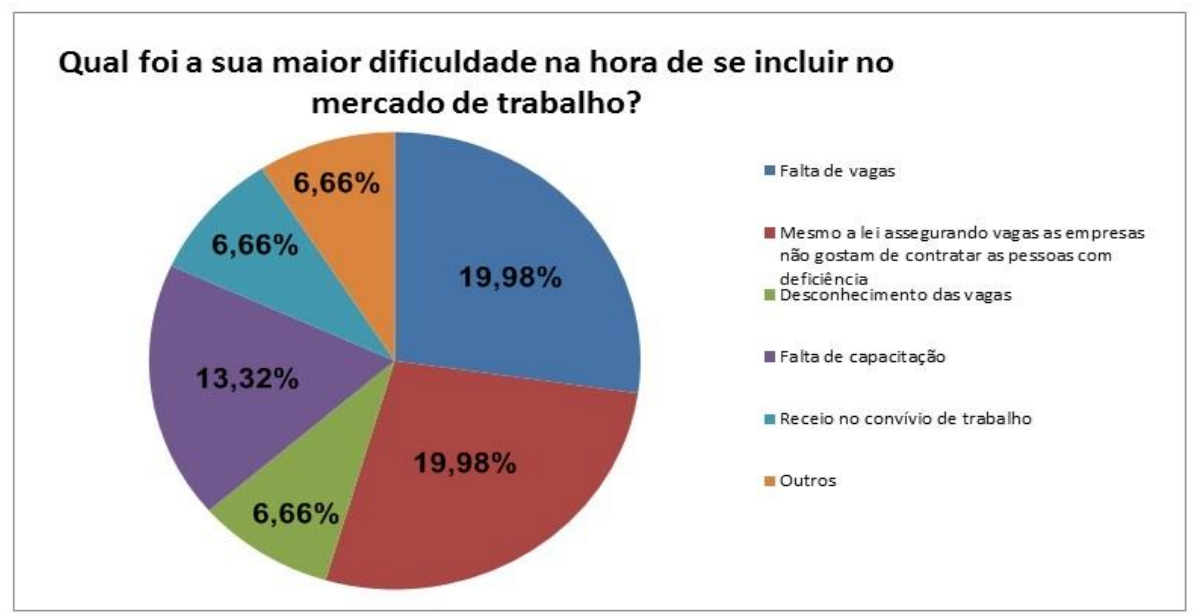

Gráfico 2 - Fatores que dificultam a inclusão das pessoas com deficiência no mercado de trabalho 
Apesar da evidência de preconceito na contratação de pessoas com deficiência, 86,68\% dos colaboradores com deficiência afirmaram que nunca foram vítimas de preconceito no ambiente de trabalho, e 13,32\% disseram que foram vítimas de preconceito por parte de colegas de trabalho. Anteriormente foi apontado por $6,66 \%$ dos colaboradores com deficiência que a grande oferta de vagas para pessoas com deficiência era um fator que facilitava a sua inclusão no mercado de trabalho e, agora, $19,98 \%$ apontaram que a falta de vagas era um dos principais dificultadores para o seu ingresso no mercado de trabalho.

Foi interessante saber dos colaboradores com deficiência se, na visão deles, a empresa fizera as adaptações necessárias para atender à legislação. Sobre a sinalização, 46,62\% afirmaram que as empresas fizeram a sinalização; $19,98 \%$ alegaram que nenhuma adaptação fora realizada; $13,32 \%$ disseram que os banheiros foram adaptados; e 19,98\% responderam que foram realizadas outras adaptações necessárias.

Consultados sobre se tinham buscado capacitação para seu crescimento na empresa, 26,40\% disseram que sempre procuravam capacitar-se; 26,40\% afirmaram que às vezes o procuravam; $13,32 \%$ que raramente o procuravam; e 19,98\% alegaram que nunca procuram capacitar-se.

A pergunta seguinte foi para saber se a empresa oferecia condições para a ascensão profissional das pessoas com deficiência: 59,94\% afirmaram que às vezes tinham oportunidade; $26,64 \%$ disseram que nunca a tiveram; e 13,42\% alegaram que raramente a tiveram. Considerando que a maioria dos colaboradores com deficiência não estava permanentemente focada em melhorar a sua capacitação, conclui-se que entre os fatores que dificultam a ascensão profissional das pessoas com deficiência está a falta de capacitação.

Sobre o treinamento oferecido pela empresa, $53,28 \%$ responderam que às vezes esta oferecia treinamento, 26,64\% afirmaram que sempre o oferecia, 13,32\% disseram que raramente o oferecia e 6,67\% que nunca o oferecia. Pode-se concluir, portanto, que o treinamento não era uma preocupação permanente de grande parte das empresas, na visão dos colaboradores com deficiência.

\section{Conclusão}

A pesquisa permitiu alcançar os objetivos propostos, pois foi possível identificar, na visão dos colaboradores com deficiência, que as principais barreiras para sua inclusão no mercado de trabalho eram a falta de vagas, a falta de capacitação e as empresas que não tinham interesse em contratá-las, e o que mais a facilitou foram a sua experiência profissional e a indicação de amigos e parentes. A maioria das empresas não cumpria a Lei de Cotas e não utilizava nenhuma estratégia com esse objetivo. Também não oferecia frequentemente oportunidade de ascensão profissional para os colaboradores com deficiência, sendo que o fator que mais contribuiu foi a falta de capacitação dessas pessoas. A sugestão para a inclusão das pessoas com deficiência no mercado de trabalho de Cláudio é desenvolver uma nova pesquisa para delinear o tipo de capacitação necessária para promover a sua inclusão e, após ter sido identificada a capacitação necessária, desenvolver um projeto de extensão com o objetivo de orientá-las e capacitá-las de acordo com as exigências do mercado.

A hipótese levantada foi parcialmente confirmada. Foi verificado que, entre os principais fatores que dificultavam a inclusão das pessoas com deficiência nas grandes e médias empresas de Cláudio, estava o fato de que grande parte delas contratava apenas para cumprir uma exigência legal, e isto não assegura a efetiva integração no ambiente de trabalho. A maioria das empresas pesquisadas não cumpria a Lei de Cotas. Verificou-se também que não havia preocupação das empresas em orientar seus gestores e funcionários para lidarem com essas pessoas. Foi possível confirmar também que a maioria das pessoas com deficiência não possuía a qualificação necessária para atenderem às exigências das empresas pesquisadas. Identificou-se que havia uma preocupação das empresas com a acessibilidade, pois fizeram as adaptações necessárias nas empresas; nem todas as adaptações, porém, foram percebidas pelos colaboradores com deficiência. Apesar de grande parte dos colaboradores com deficiência alegar que nunca sofreu 
discriminação por parte dos colegas da empresa, verificou-se que, sob o ponto de vista das pessoas com deficiência, existia discriminação por parte das empresas em contratar pessoas com deficiência. Não foi possível levantar dados sobre o incentivo dos órgãos públicos para contratação de pessoas com deficiência.

Foi possível também traçar o perfil das pessoas com deficiência que trabalhavam nas médias e grandes empresas do município de Cláudio que possuíam mais de cem funcionários. Eram homens entre trinta e cinquenta anos, que trabalhavam na empresa havia mais de dez anos, possuíam ensino fundamental e tinham deficiência física.

Portanto, de acordo com os dados levantados e analisados, pode-se concluir que entre os fatores que mais dificultam a inclusão das pessoas com deficiência no mercado de trabalho e a sua ascensão profissional dentro das organizações em que trabalham está a sua falta de capacitação.

\section{Referências Bibliográficas}

ANACHE, Alexandra Ayach. O deficiente e o mercado de trabalho: concessão ou conquista? Revista Brasileira de Educação Especial, 2 (4), 119-126., 1994.

ARAUJO, Giovanni Moraes de. Legislação de segurança e saúde no trabalho. 2012. 10. ed. Rio de Janeiro: GVC, 2012. v. 1.

BRASIL. Lei $n .^{\circ}$ 10.098, de 19 de dezembro de 2000. Estabelece normas gerais e critérios básicos para a promoção da acessibilidade das pessoas portadoras de deficiência ou com mobilidade reduzida e dá outras providências. Disponível em:

<http://www.planalto.gov.br/ccivil_03/leis/18213cons.htm>. Acesso em: 12 dez. 2014.

BRASIL. Ministério do Trabalho e Emprego. A inclusão de pessoas com deficiência no mercado de trabalho. 2. ed. Brasília: MTE, SIT, 2007. 100 p. Disponível em: $<$ http://portal.mte.gov.br/data/files/FF8080812CCDAEDE012CD0A2B79F70B3/inclusao_ pessoas_defi12_07.pdf>. Acesso em: 9 dez. 2014.

CAVALCANTE, Jouberto de Quadros Pessoa; JORGE NETO, Francisco Ferreira. O portador de deficiência no mercado formal de trabalho. Disponível em:

<http://www.mpgo.mp.br/portalweb/hp/41/docs/o_portador_de_deficiencia_no_mercado_f ormal_de_trabalho.pdf $>$. Acesso em: 19 jul. 2015.

CLÁUDIO. Prefeitura Municipal. Disponível em: <http://www.claudio.mg.gov.br/int_cad.aspx?redir=sic_cad.aspx>. Acesso em: $4 \mathrm{dez}$. 2014.

CLÁUDIO. Prefeitura Municipal. Disponível em: <http://www.claudio.mg.gov.br/Materia_especifica/6487/Economia〉. Acesso em: 12 jan. 2016.

DATA VIVA. Disponível em: <http://pt.dataviva.info/profiles/bra/4mg060101/undefined?app=14>. Acesso em: 12 jan. 2016.

DEFICIÊNCIA. Wikipédia. Disponível em: <http://pt.wikipedia.org/wiki/Defici\%C3\%AAncia>. Acesso em: 7 nov. 2014.

FEDERAÇÃO BRASILEIRA DE BANCOS (FEBRABAN). A ação de recursos humanos e a inclusão de pessoas com deficiência. (Coleção Febraban de Inclusão Social). São Paulo, 2006. Disponível em:

<https://www.febraban.org.br/Arquivo/Cartilha/Cartilha_Recursos_Humanos.pdf >. Acesso em: 10 jun. 2015.

FRANCO, Ana Carolina Barros. O portador de necessidades especiais e a relação de trabalho. Universidade do Vale do Itajaí (Univali) - Centro de Ciências Jurídicas e Sociais 
(Cejurps), 2007. Disponível em:

<http://siaibib01 .univali.br/pdf/Ana\%20Carolina\%20Barros\%20Franco.pdf >. Acesso em: 26 jan. 2016.

FREITAS, Maria Nivalda de Carvalho. Inserção e gestão de pessoas com deficiência no mercado de trabalho: um estudo de caso. São João del-Rei, 2009. Disponível em: $<$ http://www.scielo.br/scielo.php?pid=S1415-65552009000500009\&script=sci_arttext $>$. Acesso em: 26 jul. 2015.

GIL, Antonio Carlos. Métodos e técnicas de pesquisa social. 6. ed. São Paulo: Atlas, 2008.

GIL, Marta (Coord. $\left.{ }^{a}\right)$. O que as empresas podem fazer pela inclusão das pessoas com deficiência. São Paulo: Instituto Ethos, 2002.

HABER, Jaques. Um panorama positivo para uma mudança necessária. 2015. Disponível em: $<$ http://blog.isocial.com.br/a-inclusao-de-profissionais-com-deficiencia-no-mercado-detrabalho-um-panorama-positivo-para-uma-mudanca-necessaria/>. Acesso em: 10 jun. 2015.

INSTITUTO BRASILEIRO DE GEOGRAFIA E ESTATÍSTICA (IBGE). Dados estatísticos. 2000. Disponível em <www.ibge.gov.br>. Acesso em: 12 set. 2014.

INSTITUTO BRASILEIRO DE GEOGRAFIA E ESTATÍSTICA (IBGE). Dados estatísticos. Disponível em <www.ibge.gov.br>. Acesso em: 12 set. 2014.

INSTITUTO BRASILEIRO DE GEOGRAFIA E ESTATÍSTICA (IBGE).Cidades@.

Disponível em:

<http://www.cidades.ibge.gov.br/xtras/perfil.php?lang=\&codmun=311660\&search=minasgerais|claudio|infograficos:-informacoes-completas>. Acesso em: 12 jan. 2016.

OLIVEIRA, Jacqueline Moreira; ARAÚJO, José Newton Garcia; ROMAGNOLI, Roberta Carvalho. Dificuldades relativas à inclusão social das pessoas com deficiência no mercado de trabalho. Pontifícia Universidade Católica de Minas Gerais (Pucminas), v. 6, n. 1, maio 2006. Disponível em:

<http://www1.pucminas.br/documentos/dificuldades_mercado_trabalho.pdf.> Acesso em: 26 jul. 2015.

OLIVEIRA, Luiza Maria Borges. Cartilha do censo 2010: Pessoas com deficiência. Secretaria de Direitos Humanos da Presidência da República (SDH/PR) / Secretaria Nacional de Promoção dos Direitos da Pessoa com Deficiência (SNPD) / Coordenação-Geral do Sistema de Informações sobre a Pessoa com Deficiência; Brasília: SDH-PR/SNPD, 2012. 32 p. Disponível em: <http://www.pessoacomdeficiencia.gov.br/app/sites/default/files/publicacoes/cartilhacenso-2010-pessoas-com-deficienciareduzido.pdf>. Acesso em: 17 nov. 2014.

OLIVEIRA, Luiza Maria Borges. O mercado de trabalho para as pessoas com deficiência. Censo 2010. Disponível em: 〈http://www.pessoacomdeficiencia.gov.br/app/node/767>. Acesso em: 25 jul. 2015.

RICHARDSON, Roberto Jarry. Pesquisa social: métodos e técnicas. 3. ed. São Paulo: Atlas, 2009.

SANTOS, Andrea Tais dos; TRAVELIN, Ana Teresa Colenci. Inserção do portador de deficiência do mercado de trabalho. Disponível em:

<http://www.centropaulasouza.sp.gov.br/pos-graduacao/workshop-de-pos-graduacao-epesquisa/007-workshop-2012/workshop/trabalhos/gestneg/insercao-do-portador.pdf > Acesso em: 12 dez. 2014. 
SERVIÇO BRASILEIRO DE APOIO A MICRO E PEQUENA EMPRESA (SEBRAE).

Critérios e conceitos para classificação de empresas. Disponível em:

<http://www.sebrae.com.br/uf/goias/indicadores-das-mpe/classificacao-empresarial>.

Acesso em: 17 jan. 2014.

SISTEMA SORRI POR UMA SOCIEDADE INCLUSIVA. Diversidade como valor em uma sociedade inclusiva. Disponível em: $\langle\mathrm{http}: / / \mathrm{www}$. sorri.com.br/diversidade_como_valor $>$. Acesso em: 15 nov. 2014.

VIOLANTE, Rômulo Rodrigues e LEITE, Pereira Lúcia. A empregabilidade das pessoas com deficiência: uma análise da inclusão social no mercado de trabalho do município de Bauru, SP. Cadernos de Psicologia Social do Trabalho, v. 14, n. 1, 2011. Disponível em:

<http://www.revistas.usp.br/cpst/article/viewFile/25717/27450>. Acesso em: 25 jul. 2015. 